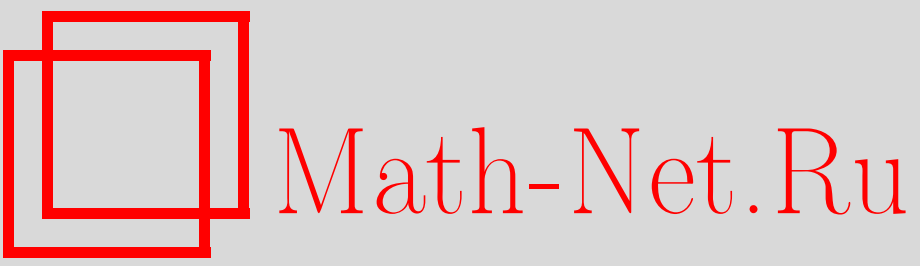

А. Г. Демешкин, А. А. Шваб, Исследование механических свойств непрерывного базальтового волокна применительно к производству композитных материалов, Вестн. Сам. гос. техн. ун-та. Сер. Физ.-мат. науки, 2011, выпуск 3(), 185-188

DOI: https://doi.org/10.14498/vsgtu939

Использование Общероссийского математического портала Math-Net.Ru подразумевает, что вы прочитали и согласны с пользовательским соглашением http: //www . mathnet.ru/rus/agreement

Параметры загрузки:

IP : 3.85 .5 .30

26 апреля 2023 г., 16:09:26 
УДК 539.375

\title{
ЭКСПЕРИМЕНТАЛЬНОЕ ИССЛЕДОВАНИЕ МЕХАНИЧЕСКИХ СВОЙСТВ НЕПРЕРЫВНОГО БАЗАЛЬТОВОГО ВОЛОКНА ПРИМЕНИТЕЛЬНО К ПРОИЗВОДСТВУ КОМПОЗИТНЫХ МАТЕРИАЛОВ
}

\author{
А.Г. Демешкин, А.А. Шваб
}

Институт гидродинамики им. М. А. Лаврентьева СО РАН, 630090, Новосибирск, пр-т Академика Лаврентьева, 15.

E-mails: schwab@ngs.ru

\begin{abstract}
Рассматриваются вопросы, связанные с прочностными свойствами непрерывных базальтовых волокон, применительно к производству композичионных материалов. Исследуется прочность жсгута (ровинга), состоящего из 4000 непрерывных базальтовых волокон. Предложена методика определения прочностных характеристик жсута из непрерывных базальтовых волокон.
\end{abstract}

Ключевые слова: базальт, волокно, жгут, прочность, композит.

В работе исследуются прочностные свойства непрерывного базальтового волокна применительно к производству композитных материалов. Непрерывное базальтовое волокно является относительно новым продуктом на рынке. В последнее время интерес к нему растёт, поскольку материал обладает такими характеристиками, как уникальные механические свойства волокна, широкая доступность сырьевой базы для его производства и низкая себестоимость. Можно выделить основные физические характеристики, делающие базальтовое волокно привлекательным для использования в производстве. Прочность непрерывного волокна превышает прочность стали более чем в 2 раза. Волокно обладает высокой термостойкостью и хорошими электроизоляционными и звукоизоляционными свойствами. Следует отметить возможность использования композитных материалов, содержащих базальтовые нити, в условиях повышенной вибрации и знакопеременных нагрузок. Базальтовое волокно обладает химической стойкостью к агрессивным средам, а именно к воздействию растворов солей, кислот и особенно щелочей. Можно также отметить низкую гигроскопичность: в 6-8 раз ниже, чем у стекловолокна.

В последние годы в промышленности больше внимания уделяется изучению неметаллической арматуры из базальтового волокна, производство которого менее трудоемко, а сырье вполне доступно. Разрабатываются новые технологии и технологическое оборудование для производства непрерывного базальтового волокна. Эти разработки дали импульс развитию промышленного производства базальтовых волокон и позволили существенно расширить потенциальный рынок их применения.

Применение более совершенных разработок позволило значительно уменьшить расходы энергоносителей и соответственно снизить себестоимость производства непрерывного базальтового волокна.

В данной работе проведены испытания на прочностные свойства непрерывного базальтового волокна. Необходимо отметить, что физико-механические свойства базальтового волокна связаны с химическим составом базальта, и поэтому для каждого базальта проводятся отдельные испытания.

Материал базальтового волокна представлен в виде ровинга в бобине. Жгут (плеть) в ровинге состоит из 4000 волокон диаметром по 15 мкм. В дальнейшем

Александр Григоръевич Демешкин (к.ф.-м.н.), старший научный сотрудник, отдел механики деформируемого твёрдого тела. Алъберт Александрович Шваб, д.ф.-м.н., доцент, ведущий научный сотрудник, отдел механики деформируемого твёрдого тела. 
вместо слова «волокно» будем употреблять слово «нить» (в смысле непрерывного базальтового волокна).

Химический состав материала следующий: $\mathrm{SiO}_{2}-52,8 \%$; $\mathrm{TiO}_{2}-0,5 \% ; \mathrm{Al}_{2} \mathrm{O}_{3}-$ $17,2 \% ; \mathrm{Fe}_{2} \mathrm{O}_{3}-8,9 \% ; \mathrm{MgO}-6,3 \% ; \mathrm{CaO}-7,1 \% ; \mathrm{Na}_{2} \mathrm{O}-2,2 \% ; \mathrm{K}_{2} \mathrm{O}-1,6 \%$.

Отметим, что в настоящее

Таблица 1 время существуют эксперимен-

\begin{tabular}{c|c|c|c}
\hline $\begin{array}{c}\text { № об- } \\
\text { разца }\end{array}$ & $\begin{array}{c}\text { Нагрузка, } \\
\text { Н }\end{array}$ & $\begin{array}{c}\text { Количест- } \\
\text { во нитей }\end{array}$ & $\begin{array}{c}\text { Нагрузка на } \\
\text { нить, } \mathrm{H}\end{array}$ \\
\hline 1 & 16,52 & 213 & 0,078 \\
2 & 1,640 & 198 & 0,082 \\
3 & 1,710 & 215 & 0,079 \\
4 & 0,890 & 93 & 0,095 \\
5 & 0,822 & 94 & 0,087 \\
6 & 0,667 & 69 & 0,096 \\
7 & 0,635 & 67 & 0,095 \\
8 & 0,558 & 60 & 0,093 \\
9 & 0,490 & 48 & 0,102 \\
10 & 0,780 & 22 & 0,081 \\
\hline
\end{tabular}
ты по определению прочности короткого базальтового волокна (так называемой фибры) длиной 20 мм. Эксперименты на фибрах проводятся на специальных испытательных установках, позволяющих испытывать волокно диаметром от 20 мкм до 1 мкм [1]. Поскольку в нашем случае испытательная машина не позволяла проводить подобные эксперименты на нескольких волокнах по

Таблица 2

\begin{tabular}{c|c|c|c}
\hline $\begin{array}{c}\text { oo об- } \\
\text { разца }\end{array}$ & $\begin{array}{c}\text { Нагрузка, } \\
\times 10^{-2} \mathrm{H}\end{array}$ & $\begin{array}{c}\text { Количест- } \\
\text { во нитей }\end{array}$ & $\begin{array}{c}\text { Нагрузка на } \\
\text { нить, } \times 10^{-2} \mathrm{H}\end{array}$ \\
\hline 11 & 57 & 4 & 14,3 \\
12 & 90 & 7 & 12,8 \\
13 & 183 & 13 & 14,0 \\
14 & 133 & 10 & 13,3 \\
15 & 165 & 13 & 12,7 \\
16 & 129 & 9 & 14,3 \\
17 & 210 & 13 & 16,1 \\
18 & 116 & 7 & 16,5 \\
19 & 66 & 4 & 16,5 \\
\hline
\end{tabular}
отдельности, то исследование прочностных свойств волокон было разбито на два этапа. На первом этапе проводились статические испытания на прочность. Так, к нескольким нитям подвешивались грузы с последующим догружением и фиксировался момент разрыва. В табл. 1 приведены результаты испытаний на разрыв нескольких нитей. Точность догрузки составляла до $0,1 \times 10^{-3} \mathrm{H}$.

При данных испытаниях вычисленная средняя прочность нити составила 0,088 Н. После этой серии экспериментов были проведены испытания, когда количество нитей было минимальным (табл. 2).

Из табл. 1 и 2 видно, что чем меньше количество нитей, тем выше вычисленная прочность одной нити. Это можно объяснить эффектом разной нагруженности нитей в процессе деформирования. Средняя прочность нити в табл. 2 составляла около $14,6 \cdot 10^{-2} \mathrm{H}$.

По результатам опытов выявилось, что испытание более 200 нитей даёт большой разброс. Поэтому была поставлена задача по испытанию всего жгута. Это определяло второй этап испытаний.

Для испытания на прочность всего жгута была использована разрывная машина фирмы Zwik/Roell 8506. Рабочая длина образца - 100 мм; на торцах жгут зажимался картонными склейками; скорость нагружения $-10^{-3}$ сек $^{-1}$.

При первых испытаниях образцов был получен значительный разброс в данных. Это объясняется тем, что при изготовлении образцов, содержащих 4000 нитей, не удавалось получить одинаковые рабочие длины в образце для всех нитей, поскольку нити имеют незначительные остаточные напряжения, появившиеся в процессе охлаждения после печи, волнообразный вид и, следовательно, различные длины в образцах из жгута (плети). Поэтому в процессе деформирования первоначально рвались короткие нити, а затем - остальные. На диаграммах «нагрузка $P$ - деформация $\varepsilon »$ это проявлялось появлением ниспадающей ветви (см. рис. 1), которая характерна только для пластических материалов и не характерна для базальта [1]. 


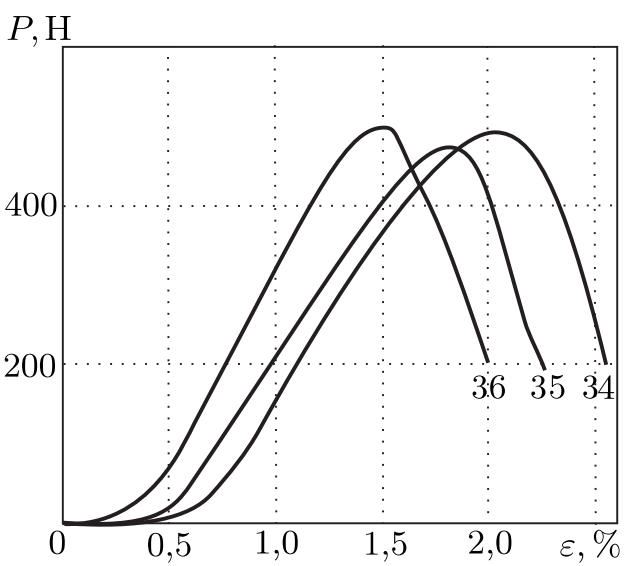

Рис. 1. Диаграммы «нагрузка $P$ - деформация $\varepsilon »$ образцов 34-36

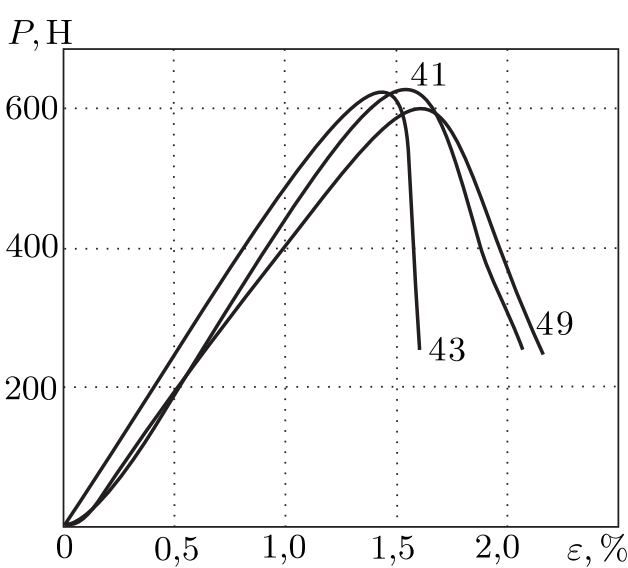

Рис. 2. Диаграммы «нагрузка $P$ - деформация $\varepsilon »$ образцов $41,43,49$

В результате анализа было предложено перед испытанием нагрузить жгут и выдержать его при нагрузке несколько дней с целью релаксации остаточных напряжений. После 10 суток выдержки при нагрузке $500 \mathrm{H}$ жгут не изменил своих характеристик, т. е. остаточные напряжения не релаксировали.

Как отмечалось выше, каждая нить в отдельности имеет незначительные остаточные напряжения, которые влияют на ее отклонение от прямолинейной формы в ненагруженном состоянии. Поскольку диаметр нити весьма мал, было предложено при изготовлении образца смачивать нити слабым вяжущим раствором на основе воды: нити смачивались, затем разглаживались (растягивались), а после этого зажимались на концах. Полученные образцы испытывались на разрыв. Результаты испытаний показали достаточно хорошую повторяемость эксперимента. На этих образцах при разрыве диаграмма имела более крутую ниспадающую ветвь (см. рис. 2). Пересчёт разрывной нагрузки на одну нить давал около $0,15 \mathrm{H}$, что можно считать близким к значениям испытаний, представленных в табл. 2. При этом прочность жгута из базальтовых нитей составила 850 МПа. Из сравнения диаграмм для образцов 34-36 и 41, 43, 49 видно, что прочность жгута, обработанного раствором, выше на $25 \%$, при этом модуль Юнга для нитей $-6,5 \cdot 10^{4}$ МПа, а деформации разрыва около $1,5 \%$.

Выводы. Результаты экспериментов показали, что поскольку в реальных конструкциях используется жгут, его прочностные свойства (в конструкциях) будут несколько ниже прочности фибры.

Отработана методика эксперимента на жгуте, имеющем 4000 базальтовых нитей диаметром 15 мкм. Подобная методика позволяет проводить испытания различных жгутов из базальтового непрерывного волокна.

Проведённые эксперименты по исследованию прочностных и деформационных свойств нитей (непрерывного базальтового волокна) показали влияние остаточных напряжений на результаты эксперимента.

Работа выполнена при поддержке РФФИ (проект № 11-01-00522) и в рамках интеграционного проекта СО РАН № 72 . 


\section{БИБЛИОГРАФИЧЕСКИЙ СПИСОК}

1. Sim J., Park C., Moon D. Y. Characteristics of basalt fiber as a strengthening material for concrete structures // Composites. B, 2005. Vol. 36, no. 6-7. Pp. 504-512.

Поступила в редакцию $17 / \mathrm{II} / 2011$;

в окончательном варианте - 27/V/2011.

MSC: 74C05; 74-05, 74K05

RESEARCH INTO THE MECHANICAL PROPERTIES OF CONTINUOUS BASALT FIBRE RELATING TO COMPOSIT MATERIALS MANUFACTURE

\section{A. G. Demeshkin, A. A. Schwab}

M. A. Lavrentyev Institute of Hydrodynamics, Siberian Branch of RAS,

15, Lavrentyeva pr., Novosibirsk, 630090, Russia.

E-mails: schwab@ngs.ru

The questions on the mechanical properties of continuous basalt fibres are considered in the work relating to the manufacture of composite materials. Durability of a plait, consisting of 4000 continuous basalt fibres is investigated. The definition technique of the mechanical characteristics of a continuous basalt fibres plait is offered.

Key words: basalt, fibre, plait, durability, composite.

Original article submitted 17/II/2011; revision submitted $27 / \mathrm{V} / 2011$.

Aleksander G. Demeshkin (Ph.D. (Phys. \& Math.)), Senior Researcher, Dept. of Solid Mechanics. Albert A. Schwab (Dr. Sci. (Phys. \& Math.)), Leading Research Scientist, Dept. of Solid Mechanics. 